\title{
A Comparative Study Of Preloading Efficacy Of Ringer's Lactate V/S 6\% Heta Starch Solutions In Preventing Hypotensionfollowing Spinal Anaesthesia.
}

\author{
DrSheikh Imran ${ }^{1}$, DrSampathilaPadmanabha ${ }^{2}$,DrHabeeb Rehman ${ }^{3}$, \\ Dr Ayaskant Sahoo ${ }^{4}$ \\ ${ }^{1}$ Yenepoya Medical College, Yenepoya University, Deralakatte, Mangalore-575018, India.
}

\begin{abstract}
Hypotension during spinal anaesthesia is common and can cause significantmorbidity and mortality. Prior to spinal anaesthesia fluid administration isrecommended to reduce the incidence of hypotension and this is referred to aspreloading. Crystalloids and colloids are routinely tried as pre loading fluids but there is still considerable debate over their effectivenessas a pre loading. A comparative study was under taken to compare the hemodynamic changes of Ringers lactate v/s Hydroxy ethyl starch in 60 ASA grade-I \&II patients posted for lower abdominal and lower limb elective surgeries and allocated into two groups. Each patient was administrated either Ringer's lactate solution at $10 \mathrm{ml} / \mathrm{Kg}$ body or 6\% Hydroxy ethyl starch at $10 \mathrm{ml} / \mathrm{Kg}$ over a period of 20 minutes before spinal anaesthesia. Following spinal anaesthesia mean arterial pressure were recorded at regular intervals. We found that hydroxy ethyl starch is more effective than lactated Ringer's solution as a pre loading fluid in prevention of hypotension following spinal anesthesia. However, we also concluded that incidence of hypotension was only reduced but not completely eliminated in this study.
\end{abstract}

Keywords: Hypotension, Pre-loading, Ringer's lactate, Hydroxy ethyl starch, Spinal anaesthesia.

\section{INTRODUCTION}

Pre loading is infusion of $10-20 \mathrm{ml} / \mathrm{kg}$. of intravenous fluids prior to procedures like spinal anaesthesia $^{(1)}$, epidural anaesthesia and induction of general anaesthesia with drugs which likely to have hypotension. The aim is to load the intravascular compartment which is likely to increase following intervention by anaesthesiologist to prevent hypotension. Crystalloids and colloids are tried as pre loading fluids. Supporters who promote crystalloids ${ }^{(2,3,4,5)}$ will highlight all the advantages such as easily availability, less reactions and cheap. Those who support colloids mention about the intravascular expansion capability, less volume required and long duration of action in-spite of high cost and fear of allergic reactions ${ }^{(6,7,8,9)}$. Following spinal anaesthesia, hypotension is a commonly seen because of autonomic blockade which is 2 segments higher than the sensory block ${ }^{(2,3)}$. To prevent hypotension pre loading was routine practice with Ringers lactate or N.S. but it is not very efficient in preventing hypotension as only $1 / 3$ of administered dose of RL or NS will remain in the intravascular compartment which may explain why hypotension associated with spinal anaesthesia cannot be completely eliminated by crystalloid preloading. And also the value of preloading has been questioned from time and time again. Too much crystalloids cause overloading of pulmonary circulation resulting in signs of overhydration $^{(\mathbf{1 0 )}}$, to prevent this small volumes of colloids are tried. 6\% Hetastarch proved to be safe colloid and widely used in all situations. The aim of our study was to compare the efficacy of a crystalloid to that of colloids in reducing the incidence and severity of hypotension in spinal anaesthesia for lower abdominal surgery. The study was also aimed to find out any side effects following infusion by either of the fluids.

\section{MATERIAL AND METHODS}

After obtaining approval from institutional ethics committee, all the patients were fully explained about the study procedure. Then written informed consent was obtained from patients.

Inclusion Criteria: Patients belonging to American Society of Anaesthesiologist (ASA) Grade- I \& II, Weight 40 to $80 \mathrm{Kgs}$, in the age group of 20 to 60 years of both sexes and undergoing various elective operations under spinal anaesthesia where minimal blood loss is anticipated.Exclusion Criteria: Any patient below 12 years, pregnant patients, patients with cardiovascular, respiratory and central nervous system disorders, patients requiring supplementation of general anesthesia, patients with renal disease. Routine investigations for all cases like complete hemogram, urine analysis, blood grouping and Rh typing, electrocardiogram (for patients over 40 years of age), chest X-ray, Random blood sugar was done.Preanesthestic evaluation was done on the previous day of surgery.All patients were pre-medicated with tablet lorazepam $2 \mathrm{mg} 60$ minutes before shifting to the operation theater.A peripheral intravenous line with 18 gauze cannula was secured in one of the upper limb. Volume of infusion was determined according to body weight. 
Patients in group- $\mathrm{R}$ received Ringer's lactate at $10 \mathrm{ml} / \mathrm{Kg}$ and patients in group- $\mathrm{H}$ received6\%Hydroxy Ethyl starch at $10 \mathrm{ml} / \mathrm{Kg}$. Both these solutions were infused over a period of 20 minutes before performance of subarachnoid block. After preloading, all patients received Ringer's Lactate solution for fluid maintenance.Baseline parameters and post spinal parameters where recorded using an electronic patient monitoring device, and entered into each patients proforma sheet.Under aseptic precautions lumbar puncture was performed with 23 gauze spinal needle (Quincke's needle) through midline approach with patient in right lateral or left lateral decubitus position at third or fourth Lumbar intervertebral space.After free flow of CSF, 3.5 of $0.5 \%$ injection bupivacaine was injected. Immediately after the injection, the spinal needle was withdrawn and patient turned to supine position.

Following spinal anaesthesia mean arterial pressure were recorded at following intervals 1,5,10,15,30,45,60,90 minutes and 3 hours after spinal anaesthesia. Rescue medications where ever administrated were recorded.Sensory level of blockade was checked after 5 minutes using pin prick method.

Hypotension was defined as a decrease in the mean arterial pressure by more than $25 \%$ from the initial baseline level.Hypotension was managed with increase in fluid infusion rate and administering $100 \%$ oxygen by mask. If hypotension still persists, despite the above measures, injection mephenteraminesulphate was administered intravenously $6 \mathrm{mg}$ bolus and repeated until the blood pressure increased to acceptable levels.

\section{RESULTS}

Both the groups were comparable in relation to age, weight or sex. (Figure 1, 2, 3)

In patients who received Ringer's lactate in group- $\mathrm{R}$ as a preloading fluid, the mean of mean arterial pressure was $99 \mathrm{~mm} \mathrm{Hg}$ before spinal anesthesia. The mean of mean arterial pressure was $88 \mathrm{~mm} \mathrm{Hg}$ after 1 minute,

$76 \mathrm{~mm} \mathrm{Hg}$ after 5 minutes, $75 \mathrm{~mm} \mathrm{Hg}$ after 10 minutes and maximum drop was up to $71 \mathrm{~mm} \mathrm{Hg}$ after 15 minutes. There was gradual increase in mean arterial pressure after 60 minutes. The mean of mean arterial pressure was $83 \mathrm{~mm} \mathrm{Hg}$ after 60 minutes, $86 \mathrm{~mm} \mathrm{Hg}$ after 90 minutes and $89 \mathrm{~mm} \mathrm{Hg}$ after 3 hours post block.(Figure 4).In patients who received 6\% Hydroxy ethyl starch in group-H as a preloading fluid, the mean of mean arterial pressure was $100 \mathrm{~mm} \mathrm{Hg}$ before spinal anesthesia. The mean of mean arterial pressure was 91 $\mathrm{mm} \mathrm{Hg}$ after 1 minutes, $79 \mathrm{~mm} \mathrm{Hg}$ after 5 minutes, $77 \mathrm{~mm} \mathrm{Hg}$ after 10 minutes and maximum drop was up to $77 \mathrm{~mm} \mathrm{Hg}$ after 10 minutes. There was gradual increase in mean arterial pressure after 60 minutes.

The mean of mean arterial blood pressure was $85 \mathrm{~mm} \mathrm{Hg}$ after 60 minutes, $88 \mathrm{~mm} \mathrm{Hg}$ after 90 minutes and $91 \mathrm{~mm} \mathrm{Hg}$ after 3 hours post block.(Figure 5).Comparing the two groups hypotension was in either of the groups but the degree of hypotension was more with Ringer's Lactate group.(Figure 6).Also the requirement of rescue medication as mephentramine was more with the Ringer's Lactate group. Number of patients requiring injection mephentermine in group- $\mathrm{R}$ was $7(63.6 \%)$ and in group-H 4 (36.4\%).(Table 1).Statistically significant $(\mathrm{p}<0.05)$ values were seen at 1 minute and 60 minutes with lesser drop in mean of mean arterial pressure in $6 \%$ Hydroxy ethyl starch group in comparison to Ringer's lactate group following spinal anaesthesia.

\section{DISCUSSION}

Till date arterial hypotension has remained the most dreaded complication of spinal Anesthesia, which needs special attention. Deaths associated with spinal hypotension continue to be reported. Great majority of such casualties are caused by a decrease in cardiac output, where coronary and cerebral blood flow becomes inadequate although other causative factors have also been implicated.

In our study, arterial hypotension has been defined as the fall in blood pressure by $25 \%$ from the basal mean arterial pressure. Incidence of hypotension in our study varies from 30-70\% depending upon a number of factors such as level of sympathetic blockade, site of operation, number of operation, patient's age, other coexisting disease condition, circulating blood volume. The usual management of hypotension has been directed towards use of peripheral vasoconstrictors to increase the total peripheral resistance or use of drugs with inotropic and chronotropic activity to augment the cardiac output of the heart.

The other effective method of increasing cardiac output is augmentation of venous return by expansion of blood volume. The prophylactic administration of crystalloid before spinal anesthesia has been considered a safe and effective method of reducing the incidence and extent of systemic hypotension following spinal anesthesia. Approximately $75 \%$ of any crystalloid diffuses into interstitial space, its efficacy in expansion of plasma volume is only transient.

Administration of crystalloid solution is disadvantageous in cases with renal impairment or congestive cardiac failure if infused in large volumes. Excessive administration of crystalloid may produce peripheral edema and rarely pulmonary edema with little effect on plasma volume. It is mainly seen in compromised patients with increased pulmonary vascular resistance, especially after the sympathetic block wears off.

Recent studies have advocated the prophylactic administration of colloids for prevention of hypotension during spinal anesthesia. Administration of colloids is a more logical choice in prevention of 
hypotension during spinal anesthesia since it remains in the intravascular compartment for prolonged periods due to its physical properties.

In our study after subarachnoid block, there was progressive fall in blood pressure up to 20-30 minutes and maximum hypotension occurred between 5-15 minutes. In our study, incidence of hypotension has been found to be higher in group-H (Ringer's lactate group) in comparison to group-H (Hydroxy ethyl starch group). We found that Hydroxy ethyl starch is superior than Ringer's lactate as preloading fluid in preventing hypotension following spinal anesthesia but does not completely eliminate hypotension.

Our observation was close to the study conducted by Singh J, Ranjit S et al ${ }^{(11)}$ who compared efficacy of Ringer's lactate solution as a pre loading fluid before spinal anaesthesia. One group of patients received 1000 $\mathrm{ml}$ of Ringer's lactate solution 30 minutes before spinal anaesthesia and the other group did not receive any preload. Hypotensionoccurred in both the groups and we concluded that volume preloading had no effect on the incidence of hypotension after spinal anaesthesia.

Our observation are also close to Siddik-Sayyid SM ${ }^{(12)}$ who compared colloid preload to coload during spinal anaesthesia using a preload of $500 \mathrm{~mL}$ of hydroxyl ethyl starch over a period of 15-20 min before initiation of spinal anesthesia in one group and identical fluid bolus of hydroxyethyl starch starting at the time of identification of cerebrospinal fluid. And concluded that both modalities are inefficient as single interventions to prevent hypotension.

Similar observation where made byRiesmeier $\mathrm{A}$ et $\mathrm{al}^{(13)}$ who compared the effects of crystalloid/colloid versus crystalloid administration before spinal anaesthesia on cardiac output (CO) in elderly patients and found intravascular volume preload with saline plus HES prevented a decrease of $\mathrm{CO}$, but did not prevent spinal anesthesia-induced hypotension.

The more stable hemodynamic status observed after colloid administration relates to the fact that colloid solution is retained in intravascular compartment for longer time than crystalloids. Rapid redistribution of crystalloids in extravascular non-functional interstitial space is fast enough. Hence, it is not possible to infuse them fast enough to maintain intravascular volume and avoid intravascular hypotension during spinal anesthesia.

As colloid solutions contain large molecules and therefore do not decrease plasma colloid pressure as much as crystalloid solutions and hence intravascular volume is well maintained as compared to crystalloid administration.

In our study, we did not come across any allergic reactions to hydroxyl ethyl starch and found that hydroxyl ethyl starch is superior to Ringer's lactate solution in prevention of hypotension following spinal anesthesia. Incidence of hypotension in hydroxy ethyl starch group is decreased but not completely eliminated.

Studies show that Hydroxy ethyl starch also has several other advantages such as prophylaxis against venous thrombosis and decreased allergic potential which is several times lower than that of gelatin.

\section{CONCLUSION}

We found that hydroxy ethyl starch is more effective than lactated Ringer's solution in prevention of hypotension in patients undergoing elective surgeries for lower abdomen and lower limb under spinal anesthesia. However, we also concluded that incidence of hypotension was only reduced but not completely eliminated in this study.

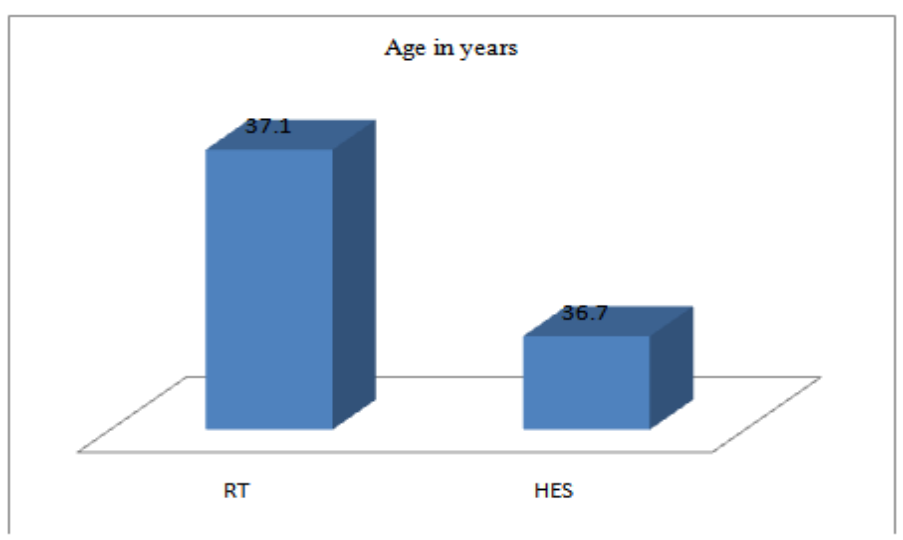

Figure-1: Showing age distribution 


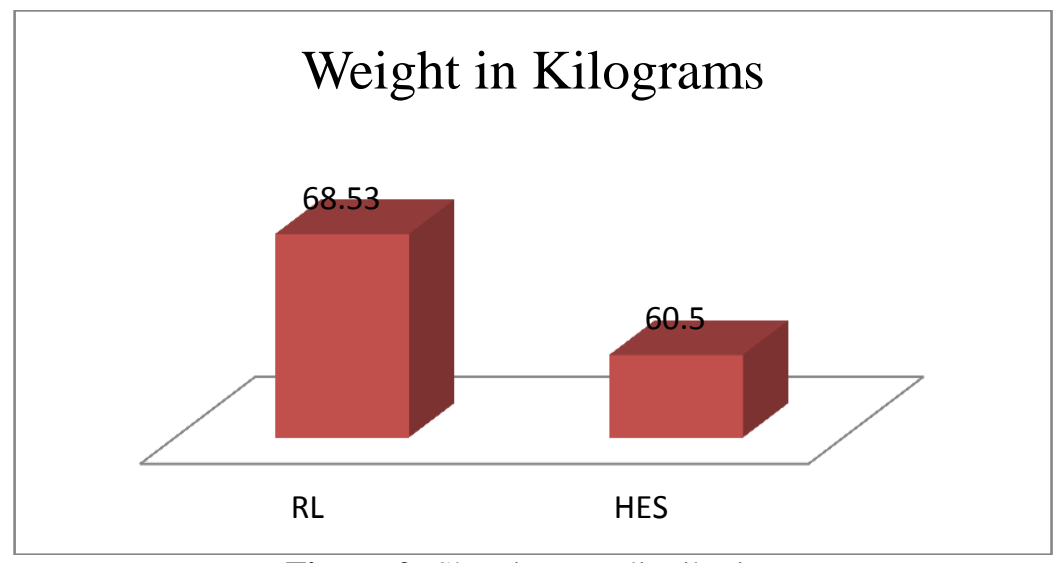

Figure-2: Showing sex distribution

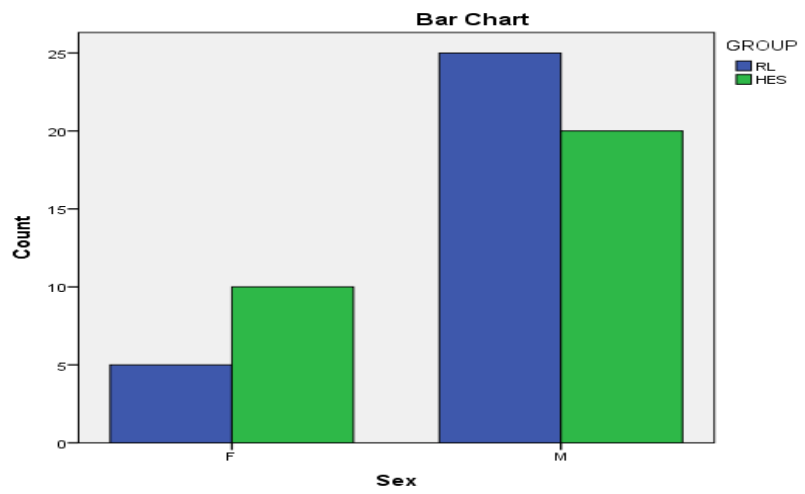

Figure-3: Showing sex distribution

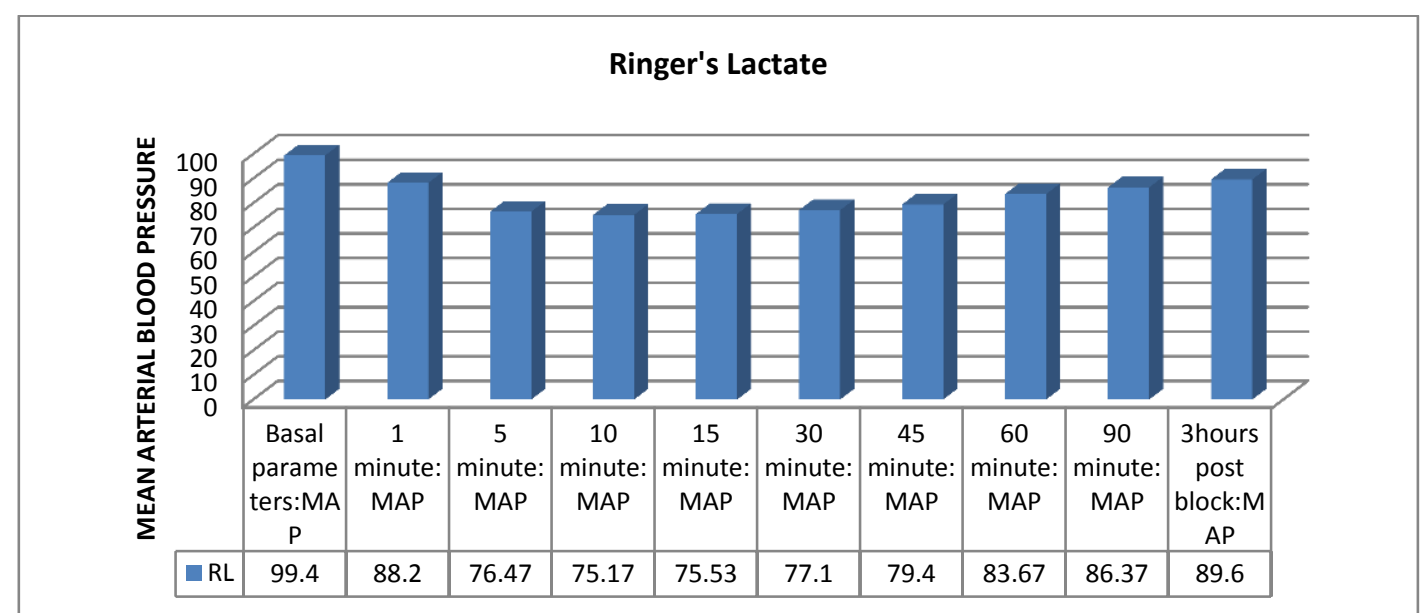

Figure-4: Showing Mean Arterial Pressure changes from baseline at Different intervals of Time after spinal anesthesia in group-R (Ringer's lactate group). 


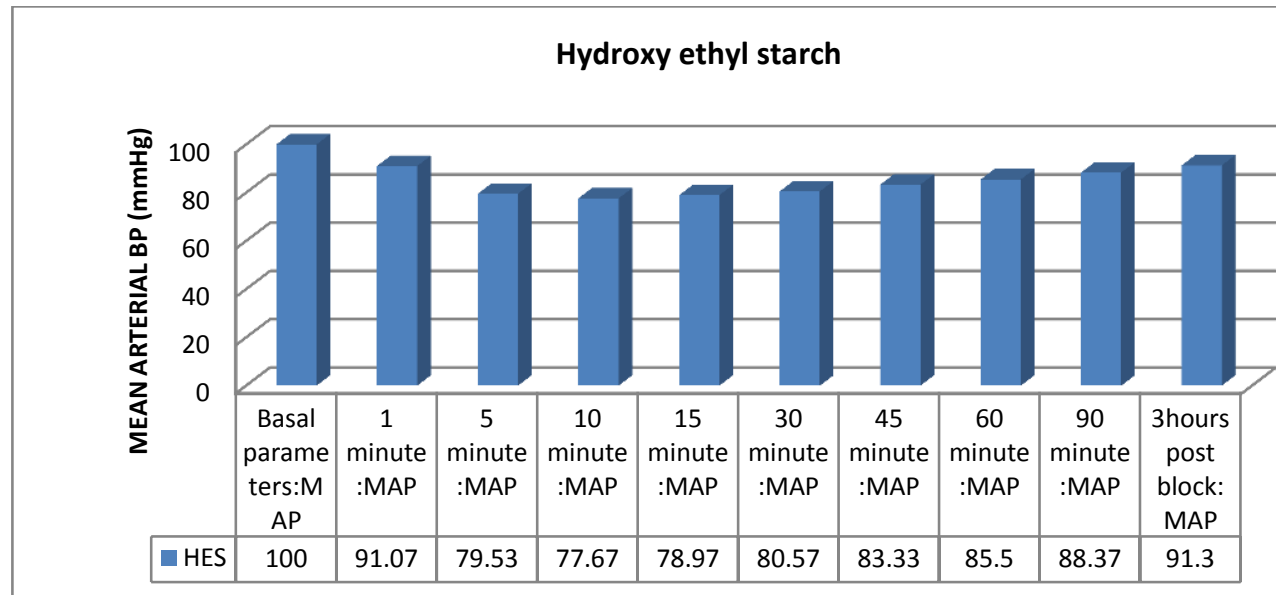

Figure-5:

Showing Mean Arterial Pressure changes from baseline at Different intervals of Time after spinal anesthesia in group- $\mathrm{H}$ (Hydroxy ethyl starch group).

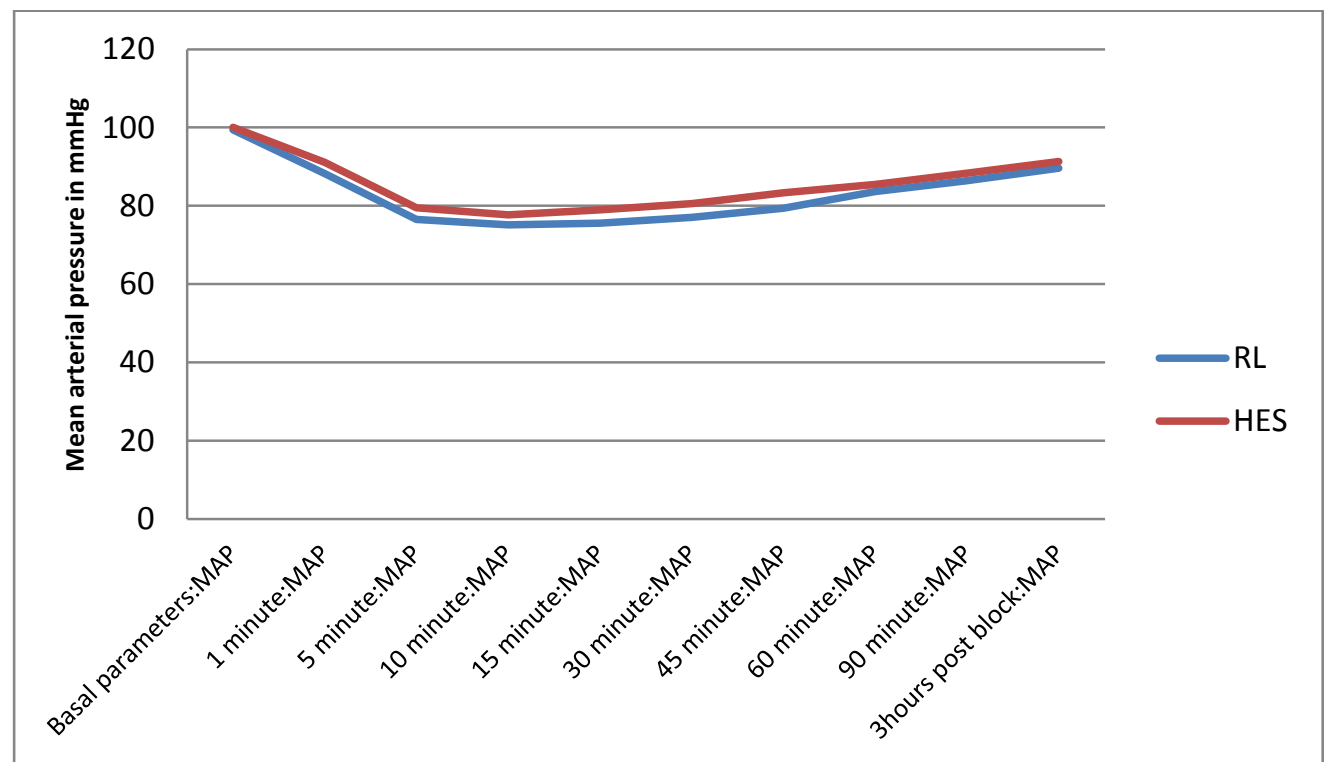

Figure-6: Showing Mean Arterial Pressure at Different intervals of Time after spinal anesthesia in both groups.

\begin{tabular}{|c|c|c|c|c|c|c|}
\hline \multicolumn{7}{|c|}{ Crosstab } \\
\hline & & & & \multicolumn{2}{|c|}{ GROUP } & \multirow[t]{2}{*}{ Total } \\
\hline & & & & $\mathrm{RL}$ & HES & \\
\hline \multirow{4}{*}{ Rescue drug:Mephentramine } & & Count & & 7 & 4 & 11 \\
\hline & $6 \mathrm{mg}$ & $\begin{array}{l}\% \quad \text { within } \\
\text { drug:Mephentramine }\end{array}$ & Rescue & $63.6 \%$ & $36.4 \%$ & $100.0 \%$ \\
\hline & & $\%$ within GROUP & & $100.0 \%$ & $100.0 \%$ & $100.0 \%$ \\
\hline & & Count & & 7 & 4 & 11 \\
\hline \multirow{2}{*}{\multicolumn{2}{|c|}{ Total }} & $\begin{array}{l}\% \quad \text { within } \\
\text { drug:Mephentramine }\end{array}$ & Rescue & $63.6 \%$ & $36.4 \%$ & $100.0 \%$ \\
\hline & & $\%$ within GROUP & & $100.0 \%$ & $100.0 \%$ & $100.0 \%$ \\
\hline
\end{tabular}

Table-1: Showing number of patients requiring injection Mephentermine 


\section{REFERENCES}

[1] Wylie and ChurchillDavidson's A Practice of Anaesthesia. 6th edition.

[2] BarashClinical Anesthesia 5th edition p-374

[3] Miller Roland D Miller's Anaesthesia. - 7th Ed Chapter-54

[4] Perel P, Roberts I, Ker K et al. "Colloids versus crystalloids for fluid resuscitation in critically ill patients". Cochrane Database of Systematic Reviews 2013, Issue 2

[5] Mojica JL, Melendez HJ, Bautista LE et al. "The timing of intravenous crystalloid administration and incidence of cardiovascular side effects during spinal anesthesia: the results from a randomized controlled trial". Anesthesia \& Analgesia. 2002 Feb;94(2):432-7

[6] Fu-qing Lin, Cheng Li, Li-jun Zhang, Shu-kun Fu, Guo-qiang Chen, Xiao-hu Yang, Chun-yan Zhu, and Quan Li et al "Effect of Rapid Plasma Volume Expansion during Anesthesia Induction on Haemodynamics and Oxygen Balance in Patients Undergoing Gastrointestinal Surgery".International Journal Medical Sciences. 2013; 10(4): 355-361.

[7] Sharma SK, Gajraj NM, Sidawi JE et al "Prevention of hypotension during spinal anaesthesia : A comparision of intravascular administration of Hetastarch versus Lactated Ringer's solution.” Anaesthesia \& Analgesia.1997 Jan:84(1):111-4

[8] Buggy DJ, Power CK, Meeke R, O’Callaghans S, Moran C, O'Brien GT et al “ Prevention of spinal anaesthesia induced hypotension in elderly: I.M. Methoxamine or combined Hetastarch\& Crystalloid." British Journal Of Anaesthesia.1998 Feb;80(2):199-203

[9] Marhofer P, Faryniak B, Oismüller C, Koinig H, Kapral S, Mayer N et al. "Cardiovascular effects of 6\% hetastarch and lactated Ringer's solution during spinal anesthesia”.Regional Anesthesia \& Pain Medicine. 1999 Sep-Oct;24(5):399-404.

[10] Phillip O. Bridenbaugh, Nicholas M. Greene, Sorin J. Brull . Spinal Neural blockade. In: Michael J cousins, Phillip O. Bridenbaugh ed. Neural blockade in Clinical Anesthesia and Management of Pain.Third edition. Philadelphia: Lippincott Raven.

[11] Singh J, Ranjit S, Shrestha S, Sharma R, Marahatta SB et al "A study to investigate the effects of volume preload on changes of patient's hemodynamic". Kathmandu University Medical Journal (2010), Vol. 8, No. 2, Issue 30, $216-221$

[12] Siddik-Sayyid SM, Nasr VG, Taha SK, Zbeide RA, Shehade JM, Al Alami AA, Mokadem FH, Abdallah FW, Baraka AS, Aouad MT et al"A study to compare colloid preload to coload during spinal anaesthesia for elective caesarean delivery". International Anesthesia Research Society Vol. 109, No. 4, October 2009

[13] Riesmeier A, Schellhaass A, Boldt J, Suttner S. et al"A study to compare the effects of crystalloid/colloid versus crystalloid administration before spinal anaesthesia on cardiac output $(\mathrm{CO})$ in elderly patients undergoing transurethral resection of the prostate".International Anesthesia Research Society Vol. 108, No. 2, February 2009 